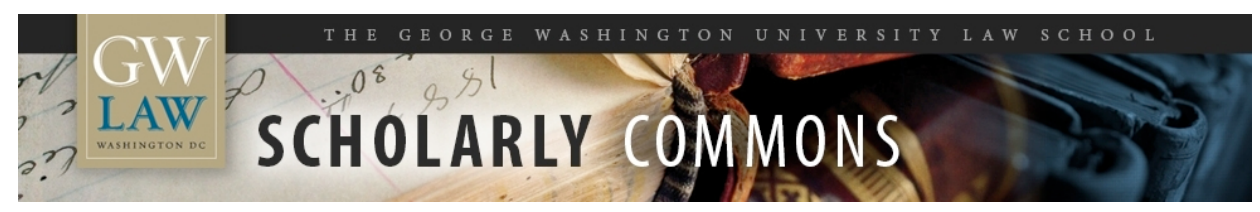

GW Law Faculty Publications \& Other Works

Faculty Scholarship

2017

\title{
What's Right About Knowing?
}

Naomi R. Cahn

George Washington University Law School, ncahn@law.gwu.edu

Follow this and additional works at: https://scholarship.law.gwu.edu/faculty_publications

Part of the Law Commons

\section{Recommended Citation}

Naomi Cahn, What's Right About Knowing?, 4 J. L. \& BIOSCIENCES 377 (2017). ; GWU Law School Public Law Research Paper No. 2017-55; GWU Legal Studies Research Paper No. 2017-55. Available at SSRN: http://ssrn.com/abstract=3011639

This Article is brought to you for free and open access by the Faculty Scholarship at Scholarly Commons. It has been accepted for inclusion in GW Law Faculty Publications \& Other Works by an authorized administrator of Scholarly Commons. For more information, please contact spagel@law.gwu.edu. 


\title{
What's right about knowing?
}

\author{
Naomi Cahn*
}

\author{
George Washington University Law School, Washington, DC 20052, USA \\ Corresponding author. E-mail: ncahn@law.gwu.edu
}

KEYWORDS: Reproductive technologies, sperm donation, anonymity, donor-conceived, sperm banking, egg banking

In Sperm donor anonymity and compensation: an experiment with American sperm donors, ${ }^{1}$ the authors contribute to our knowledge about the impact of moving toward a system of known sperm donation in the USA by surveying a population of active and inactive actual sperm donors. Their conclusions-slightly more than a quarter would refuse to contribute, while the remaining donors would require an additional $\$ 60$ per donation - are interesting and useful in modeling the implications of moving towards a new regime that allows for limited disclosure.

Yet this study must be placed in a larger context that considers not just the market for sperm donors ${ }^{2}$ but also the implications of anonymity and disclosure for family formation. A number of developments call into question the ethics of anonymity and, indeed, the ability to 'promise' anonymity itself: (i) donor-conceived offspring increasingly advocating for additional information about their donors; (ii) growing numbers of families that cannot 'cover' their use of a donor; (iii) improved searching techniques available from genetic testing and the internet; (iv) claims that lack of access to information violates offsprings' right under the Convention on the Rights of the Child; and (v) more technological means for using the intending parents' own gametes (through, for example, in vitro gametogenesis).

Providing information on the financial implications of ending complete anonymity is thus a useful exercise in assessing the consequences of changing the current US

\footnotetext{
Naomi Cahn is the Harold H. Greene Chair at the George Washington University Law School.

1 Glenn Cohen et al., Sperm Donor Anonymity and Compensation: An Experiment With American Sperm Donors, 3 J. L. \& Biosci. 468 (2016).

2 I realize that the term 'donor' in relation to the child is controversial, but I chose to use this term to simplify the discussion.
}

\footnotetext{
(C) The Author 2017. Published by Oxford University Press on behalf of Duke University School of Law, Harvard Law School, Oxford University Press, and Stanford Law School. This is an Open Access article distributed under the terms of the Creative Commons Attribution-NonCommercial-NoDerivs licence (http://creativecommons.org/licenses/by-nc-nd/4.0/), which permits non-commercial reproduction and distribution of the work, in any medium, provided the original work is not altered or transformed in any way, and that the work is properly cited. For commercial re-use, please contact journals.permissions@oup.com
} 
system, and the authors' thoughtful caveats on both the 'underground' market and fertility tourism provide even more grounding for assessment. This brief comment summarizes these contextual issues as a way of adding depth to the article's implications.

\section{THE STUDY}

In an effort to test how ending anonymity in the USA would affect men's willingness to donate sperm, the researchers conducted a study with actual donors. A sperm bank employee invited 67 active donors and 204 inactive donors to participate in the study; all of the active donors and 94 of the inactive donors responded. More than half of the study participants (90/161) were anonymous donors (p. 477), and 52 of the anonymous donors were active (p. 479). Subjects were then randomly assigned either to a treatment or control condition; those in the treatment condition were given a description of the United Kingdom sperm donor system, while those in the control condition did not (p. 478). Members of each group were then asked how much money they needed to be given to donate to an identity-release program, or whether they would not donate anything.

The study provides important data on both the cost and willingness of these anonymous donors to become known: approximately 29 per cent of the active donors would choose not to donate (p. 482) and, among those who would, the average increase in payment to donate was $\$ 60$ (p. 470).

The authors note some limitations, such as the relatively small number of active and anonymous donors (p. 479). And, indeed, using a sample of 90 anonymous donors (albeit ones who have actually passed the test to become donors) to make policy generalizations builds on a very small base. Moreover, because the particular bank from which these donors are drawn has a known id program, these donors had already made the choice to remain anonymous, so the experiment asks them to revisit an earlier decision. ${ }^{3}$

Consequently, drawing conclusions from the study is a complex enterprise. The authors note that a potential decrease of almost 30 per cent in the number of donors 'would arguably have economic implications for the market for sperm donation-both in terms of the potential costs of maintaining an adequate level of donor supply and/or the quality of the samples provided' (p. 482). Yet without knowing the size of the current donor supply — and the USA keeps no records on donor sperm, apart from those related to medical testing ${ }^{4}$ - there is no way of estimating these 'arguable' financial implications, a point they acknowledge explicitly (p. 487). Indeed, the authors note there is 'considerable uncertainty [] regarding the likely market reaction to mandatory donor identification rules and what this means for price' (p. 486).

Beyond the study, however, are numerous technological, moral and legal developments that affect its significance and its utility for moving forward toward ending anonymity.

\footnotetext{
The authors do speculate about an 'endowment' effect. (p. 487)

See eg Wendy Kramer \& NaOmi Cahn, Finding Our Families (2013).
} 


\section{OTHER DEVELOPMENTS CONCERNING SPERM DONATION, BIOLOGY,} AND CULTURE

Two technological developments provide context for the study. The first is the future of reproduction and the questions it raises about the potential need for gamete donation. The second is the virtual end of anonymity.

\section{Will we still need donors?}

There are a number of potential technologies on the horizon that will largely, although not completely, eliminate the need for donor gametes. Consider that, with the development of ICSI, many heterosexual couples no longer need sperm donation; it appears that the majority of those seeking sperm donors are now single women and lesbians, though accurate records do not exist. In addition, single men and gay male couples still need eggs (and a woman to bear them), although the costs of surrogacy inhibit demand. The use of mitochondrial replacement, which does require a donor egg, is now possible, but it involves a technologically complex procedure that will not require a significant number of donors.

And the development of in vitro gametogenesis may involve ways to produce an unlimited supply of sperm and eggs genetically related to the intended parents, largely eliminating the need for donor gametes altogether as a response to infertility. ${ }^{5}$ Instead, the majority of those seeking donors may become single men or women or those in same-sex relationships who need donor gametes to procreate whatever their fertility status. The role of anonymity in these relationships may change the dynamic underlying game donation.

The future of sperm - and egg — donation is thus under pressure from a variety of technologies, both internal and external to the reproductive market.

\section{The technology of knowing}

Advances in DNA testing, including direct-to-consumer kits, mean the ability to maintain secrecy about involvement in donor conception is questionable. Ryan Kramer swabbed the inside of his cheek; his story helps show the increased likelihood of unplanned disclosure and its associated risks. ${ }^{6}$ Of course, he knew he was donorconceived, but he is not the only donor-conceived person to use such testing. ${ }^{7}$ Overall, more than 3 million people have already used these testing kits to find information about their ancestry. ${ }^{8}$ The ubiquity of this technology challenges the maintenance of anonymity; even if banks promise not to release records, ${ }^{9}$ genetic testing could easily

5 Sonia M. Suter, In Vitro Gametogenesis: Just Another Way to Have a Baby?, 3 J.L. \& Biosci. 87, 103 (2016); Henry T. Greely, The End of Sex and the Future of Human Reproduction (2016); I. Glenn Cohen et al., Disruptive Reproductive Technologies, 9 SCI. TRAnsL. Med. (2017), http://stm.sciencemag.org/ content/9/372/eaag2959.full

6 See Wendy Kramer, Sperm Donors Who Wish To Remain Anonymous Just Shouldn't Donate, http://www.huffingtonpost.com/wendy-kramer/sperm-donors-who-wish-to-_b_7878688.html.

7 Is a cite needed for this? See eg http://www.express.co.uk/life-style/health/685599/Sperm-donors-DNAtesting-biological-father-offspring-anonymity; the Harper article infra.

8 Joyce C. Harper, Debbie Kennett \& Dan Reisel, The End of Donor Anonymity: How Genetic Testing is Likely to Drive Anonymous Gamete Donation Out of Business, 31 Hum. Reprod. 1135 (2016), https://academic. oup.com/humrep/article/31/6/1135/1749791/The-end-of-donor-anonymity-how-genetic-testing-is.

9 For example, as one bank explains: 'California Cryobank ... will always exercise our most strenuous efforts to assure donor anonymity'. http://www.spermbank.com/about/sperm-donor-confidentiality 
lead to a revealed identity, an issue that parents and donors need to consider as they 'choose' anonymity.

\section{THE INTENDING PARENTS THEMSELVES}

Sperm donation is marketed to potential parents; they are the consumers and patients. While anonymity is offered in respond to the perceived desire of parents to have 'choices', the parameters of such a demand are unclear. In one of the few studies to compare families who had chosen known versus unknown donors, the vast majority of both mothers and comothers were satisfied with the type of donor they had chosen; 'the only significant differences were that those selecting open-identity donors were more satisfied than dissatisfied and that those using unknown donors were more dissatisfied than satisfied'. 10

And, in another study comparing heterosexual-partnered mothers and single-parent mothers, the 'Partnered mothers were more likely than solo mothers to feel neutral, ambivalent or negative about having used an identifiable donor $(P<0.05)$, and were less likely to consider children's knowledge of their genetic origins as extremely important'. ${ }^{11}$ Because heterosexual partnered women are becoming less likely to need sperm donors, the interests of solo mothers deserve more respect and attention. Of course, not all single mothers would choose identity-release donors. ${ }^{12}$

As one more aspect of considering parents, it is unclear that moving away from anonymity would have any impact on demand (although that does suggest an avenue for future research).

\section{RESPECTING DONOR-CONCEIVED OFFSPRING}

The most significant contextual issue for analysing the findings of this study involves donor-conceived individuals themselves and how to account for their interests. They are not involved in the initial transactions surrounding their creation and, once born, they have interests - and, ultimately, rights -that differ from those of their parents. ${ }^{13}$

One of the problems in the past has been limitations on empirical research because of the anonymous nature of gamete donation, although more research is emerging as countries move toward disclosure. ${ }^{14}$ What this research shows is that many donorconceived individuals want to know more about their donors ${ }^{15}$, and thousands of them

10 Nanette Gartrell et al., Satisfaction With Known, Open-Identity, or Unknown Sperm Donors: Reports From Lesbian Mothers of 17-Year-Old Adolescents, 103 FERTIL. \& STERIL. 242 (2015), http://www.fertstert.org/article/S0015-0282(14)02171-2/abstract

11 Tabitha Freeman, Disclosure of Sperm Donation: A Comparison Between Solo Mother and Two-Parent Families With Identifiable Donors, 33 Reprod. BIOMED. OnLINE 592 (2016), https://www.ncbi.nlm.nih.gov/pubmed/27617789; Margaret K. Nelson \& Rosanna Hertz, DonorInsemination Motherhood: How Three Types of Mothers Make Sense of Genes and Donors, J. LGLBT FAM. STUD., http://www.tandfonline.com/doi/full/10.1080/1550428X.2016.1249585?scroll=top\&needAccess=true.

12 'Single recipients of donor sperm do not necessarily desire to use an identity-release donor, either at the time of treatment, or indeed at all.' Sophie Zadeh, Tabitha Freeman \& Susan Golombok, Absence or Presence? Complexities in the Donor Narratives of Single Mothers Using Sperm Donation, 31 Hum. ReProd. Update 117-124 (2016).

13 For example, Catherine Ross, Lessons in Censorship (2015).

14 Eric Blythet al., Donor-Conceived People's Views and Experiences of their Genetic Origins: A Critical Analysis of the Research Evidence, 19 J. L. \& MED. 769 (2012).

15 For example, Margaret Nelson, Rosanna Hertz \& Wendy Kramer, Making Sense of Donors and Donor Siblings: A Comparison of the Perceptions of Donor-Conceived Offspring in Lesbian-Parent and Heterosexual-Parent Families, 
have signed up for voluntary registries to try to find a match with their donors and donor-conceived siblings. ${ }^{16}$ Studies also show that donor-conceived offspring use different terms to refer to their 'donors', ranging from donor, dad or father, although the terminology does not necessarily indicate a desire for a more formal parental relationship. ${ }^{17}$

In discussing anonymity, there are two layers of disclosure. The first is telling children they are donor-conceived; the second is obtaining access about the donor. Each is briefly discussed below.

In the first issue, disclosure itself-and early-has benefits for family dynamics, as one study of families formed through egg donation reported. In comparing parents who told their children before they turned 8 with those who waited, researchers reported that the early disclosing parent felt no anxiety relating to disclosure and expressed full confidence that they had done the right thing. On the other hand, the non-disclosing families experienced high levels of anxiety as they waited for the 'right time' to tell. In another study that reviewed 43 studies (36 different populations) of how heterosexual couples who had used donor gametes approached the disclosure decision-making process, the researchers found that the parents who intended to inform their child that they were donor-conceived were more likely to favor donor-identifying information, and they emphasized children's best interests and their rights to know that they are donor-conceived, they listed honesty as a core element of trust in the parent-child relationship, and noted the stress of keeping a secret. ${ }^{18}$ The non-disclosing parents similarly emphasized the best interests of their children, but saw no benefit from disclosure, wanted to protect the child from stigma or other damage, and fully believed they could keep the secret (outside of a health emergency). The authors noted that, ' $[t]$ he impact of legislation on parents' disclosure decision is unclear. It is difficult to separate the possible impact of regulations from cultural changes in attitudes over time'. ${ }^{19}$ The disclosure decisions are-for obvious reasons - more straightforward in single parent and LGBT families. ${ }^{20}$

In the second issue, access to identifying information, some, but not all, donorconceived individuals want access to such information, regardless of whether it results in any subsequent relationship or even whether they wish to make contact with the

7 FAmily Res. 142 (2013); Sherina Persaud et al., Adolescents Conceived Through Donor Insemination in MotherHeaded Families: A Qualitative Study of Motivations and Experiences of Contacting and Meeting Same-Donor Offspring, 31 CHILDREN \& Soc. 13 (2017), http://onlinelibrary.wiley.com/doi/10.1111/chso.12158/epdf.

16 For example, the Donor Sibling Registry has helped more than 14,000 members of donor-conceived families connect with one another, https://donorsiblingregistry.com/

17 In one study, the 'majority of offspring who talked about their donor in the open-ended responses referred to him as "donor," yet 'almost one-third used a term that included father or dad (father, biological father, donor father, and dad)'. Vasanti Jadva et al., The Experiences of Adolescents and Adults Conceived by Sperm Donation: Comparisons by Age of Disclosure and Family Type, 24 HuM. REPRoD. 1909, 1917 \& Table IV (2009), https://academic.oup.com/humrep/article-lookup/doi/10.1093/humrep/dep110; see Nelson, Hertz \& Kramer, supra note 15 (pdf at 8).

18 Astrid Indeku et al., Factors Contributing to Parental Decision-Making in Disclosing Donor Conception: A Systematic Review, 10 Hum. ReProd. Update 714 (2013), https://academic.oup.com/ humupd/article/19/6/714/838778/Factors-contributing-to-parental-decision-making.

19 Id.

20 Naomi Cahn \& Wendy Kramer, Let's Get Rid of the Secrecy in Donor-Conceived Families, Dec. 13, 2013, http://www.slate.com/blogs/xx_factor/2013/12/13/donor_conceived_children_deserve_to_know_the_ truth_about_their_origins.html. 
donor. ${ }^{21}$ Moreover, studies explain that access to identifying information may help offspring socially, emotionally, psychologically, and physically; offspring explain that this will help them in numerous ways, such as offering a better understanding of their social, cultural, and biographical heritage, satisfying their curiosity, completing their identity, and learning about medical risks. ${ }^{22}$

Part of the process of reaching adulthood is the creation of a personal identity. Parents who choose to use donor gametes rather than adopt often do so because they want a child to whom they are genetically related as part of their own expression of individual values. ${ }^{23}$ Their children may similarly want to explore both halves of their genetic lineage in coming to their own conclusions about how they think of themselves and how they want to live their lives. ${ }^{24}$

It is important to note one other significant context: the complicated and sometimes paradoxical importance of the genetic connection. ${ }^{25}$ Parents often use donor gametes so there is a genetic connection between one parent and the child; understandably, offspring may be curious about their other genetic half, and preventing them from such access perpetuates a double standard in which genes are important to parents, but not to their children.

\section{CONCLUSION}

Ultimately, the focus of this research is on information concerning the amount that donors must be paid to agree to be identified. ${ }^{26}$ Consequently, it does not explicitly address the interests of donor-conceived offspring as they grow up. ${ }^{27}$ Thus, regardless of what the research shows with respect to the financial costs of known donors, and, unless the research shows actual harm to donor-conceived offspring from identity-release, policymakers can craft an approach that reflects their society's values.

Moving toward disclosure respects not only potential relational interests but also recognizes the autonomy claims of offspring. Moreover, donor-conceived offspring

21 Eric Blythet al., Donor-Conceived People's Views and Experiences of Their Genetic Origins: A Critical Analysis of the Research Evidence, 19 J. L. MED. 769 (2012).

22 Marilyn Crawshaw et al., Can the UK's Birth Registration System Better Serve the Interests of Those Born Following Collaborative Assisted Reproduction? (2017), http://www.rbmsociety.com/article/ S2405-6618(17)30003-5/pdf

23 Tabitha Freeman, Gamete Donation, Information Sharing and the Best Interests of the Child: An Overview of the Psychosocial Evidence, 33 Monash. Bioeth. Rev. 45 (2015), https:// www.ncbi.nlm.nih.gov/pmc/articles/PMC4900443/

24 Barbara Bennett Woodhouse, 'Are You My Mother?': Conceptualizing Children's Identity Rights in Transracial Adoptions, 2 Duke J. Gender L. \& POL'y 107, 127-28 (1995)(noting the need for children to claim rights with respect to two aspects of their identity: the first is in the context of their functional, social family, and the second is their 'identity of origin').

25 Freeman, supra note 23.

26 Of course, parents may take advantage of the 'free sperm' or 'underground' markets available. See eg Susan Frelich Appleton, Between the Binaries: Exploring the Legal Boundaries of Nonanonymous Sperm Donation, 49 FAM. L.Q. 93 (2015); Cohenet al., supra note 1, at 474-75 n. 31.

27 On the other hand, Margaret Radin has suggested, in the context of baby-selling, that 'to conceive of infants in market rhetoric is likewise to conceive of the people they will become in market rhetoric, and to create in those people a commodified self-conception'. Margaret Jane Radin, Market Inalienability, 100 HARV. L. REV. $1849,1925-26$ (1987). 
have also claimed that they are the objects of discrimination because they do not have access to the identities of their biological parents. ${ }^{28}$

Even under a system of full disclosure, there certainly remains a critical distinction between 'parenting' a child and contributing gametes to the creation of the child. The legal parents have the right to make their own decisions concerning the control, care, and custody of their children, and these decisions - on their own behalf-may include disclosing details about the child's origins. Regardless of their parents' actions, however, the offspring have independent rights. An overall policy of only permitting known donors respects parental rights to raise children as they see fit while the children are minors, but respects the offsprings' rights once they are mature.

Prospective gamete provision arrangements should proceed in a legal context in which it is understood that offspring will have access to information once they become adults. Correspondingly, this means that mature offspring in donor-conceived families deserve the ability to receive information about their biological families of origin.

\section{ACKNOWLEDGEMENT}

The author thanks Glenn Cohen, June Carbone, Rosa Castro, Karen Clark, and Marilyn Crawshaw for their generous engagement with this Commentary, and Mohammad A. Zaheerudin for his research assistance. 